\title{
МЕТОДИЧЕСКИЕ ОСНОВЫ РАЗРАБОТКИ СИСТЕМЫ ПОКАЗАТЕЛЕЙ ЭКОНОМИЧЕСКОЙ БЕЗОПАСНОСТИ ПРЕДПРИЯТИЙ РОССИЙСКОГО НЕФТЕГАЗОВОГО КОМПЛЕКСА
}

\section{METHODOLOGICAL BASIS \\ OF DEVELOPMENT OF A SYSTEM \\ OF INDICATORS OF ECONOMIC SECURITY \\ FOR THE COMPANIES OF THE RUSSIAN \\ OIL AND GAS COMPLEX \\ V. Babenkov \\ I. Zhukov \\ A. Frolov}

Summary: The present paper contains a method of development of a system of indicators for evaluation of economic security of companies of Russian oil and gas complex in the present technological and geopolitical situation. Main directions of economic security are identified. Specific indicators for evaluation of economic security within these directions are proposed. A general indicator of economic security is described.

Keywords: economic security, indicators of evaluation, oil and gas and industry.
Бабенков Валерий Иванович

Д.в.н., профессор, ФГКВОУВО «Военная академия материально-технического обеспечения

им. генерала армии А.В. Хрулёва»

vi_babenkov@mail.ru

Жуков Иван Федорович

Aсnирант, ФГБОУВО «Санкт-Петербургский университет Государственной противопожарной службы Министерства Российской Федерации по делам гражданской обороны, чрезвычайным ситуачиям и ликвидации последствий стихийных бедствий» ivan-zhukov-1995@mail.ru

Фролов Александр Олегович

К.э.Н., старший преподаватель, ФГАОУ ВО «Российский государственный университет нефти и газа (национальный исследовательский университет) имени И.М. Губкина» frolov@live.ru

Аннотация: В статье предложена методика разработки системы показателей оценки экономической безопасности предприятий российского нефтегазового комплекса с учетом текущей технологической и геополитической ситуации. Идентифицированы основные направления обеспечения экономической безопасности. Предложены показатели для оценки экономической безопасности по этим направлениям, а также обобщающий показатель экономической безопасности.

Ключевые слова: экономическая безопасность, показатели оценки, нефтегазовая отрасль.

предприятия.

Переход к новому технологическому укладу [1, 14, 27, $29,36]$ трансформирует подход к обеспечению экономической безопасности предприятия [13]:

- перевод значительной части производственных процессов в цифровой формат ведет к необходимости защиты не только физической, но и информационной инфраструктуры предприятия [4, 35]. При этом уровень уязвимости информационной инфраструктуры значительно ниже, чем уровень уязвимости материальных основных фондов фирмы. В частности, доступ к информационной инфраструктуре может быть получен дистанционно, а успешная атака на информационную систему компании может заблокировать ее деятельность в полном объеме - добиться такого же эффекта при помощи атаки на физическую инфраструктура значительно сложнее; 
- выведение ряда бизнес-процессов за пределы компании и передача их на исполнение специализированным операторам [25, 26] (т. е. переход к сетевой модели организации бизнеса вместо вертикальной или горизонтально интегрированной производственной структуры, использовавшейся в предшествующих технологических укладах [28]) ведет к необходимости обеспечивать экономическую безопасность не традиционного единого предприятия, а сложного производственного комплекса (метафирмы) [19, 20, 24]. Иными словами, речь идет, во-первых, об обеспечении экономической безопасности каждого конкретного предприятия в составе метафирмы, и, во-вторых, об экономической безопасности метафирмы в целом. Это связано с тем, что нефтегазовая компания в современных условиях в значительной степени опирается на внешние, а не на собственные ресурсы, привлекая для решения профильных задач специализированные нефтесервисные предприятия. Таким образом, эффективная модель взаимодействия в рамках метафирмы предполагает наличие доступа нефтегазовой компании (как ядра метафирмы) к внешним ресурсам и способность внешних провайдеров постоянно обеспечивать нефтегазовую компанию необходимыми ей ресурсами. Данная сетевая модель функционирования значительно увеличивает объем ресурсов, которые фирма может использовать в своих интересах (возникает эффект «сервисного рычага»), но при этом является источником дополнительных рисков в том случае, если фирме по каким-либо причинам будет отказано в доступе к внешним источникам необходимых для нее ресурсов.

Поскольку метафирма представляет собой распределенное предприятие с организационной и географической точек зрения [32], ее экономическая безопасность зависит от качества взаимодействия между ее участниками. Ограничения на это взаимодействие, высокие издержки его осуществления и т. д. приведут к тому, что метафирма будет функционировать неэффективно;

- возможность непрерывного сбора информации о производственных процессах и иных хозяйственных операциях и ее обработки в режиме реального времени позволяет значительно повысить экономическую безопасность фирмы за счет того, что высокозатратные и рискованные операции первоначально реализуются преимущественно в цифровом формате (и осуществляются в материальном виде только после их полноценного тестирования в режиме цифрового двойника), а также благодаря тому, что фирма, владея полной и своевременной информацией о своей деятельности, может оперативно реагировать на неблагоприятные изменения внутренней и внешней среды и минимизировать связанные с ними риски. Отметим, что цифровой двойник, помимо технологических, решает и организационные задачи: он создает условия для эффективного взаимодействия независимых участников метафирмы (а также географически распределенных подразделений единой компании). Цифровой двойник формирует единую виртуальную среду ведения хозяйственной и производственной деятельности. Однако, как было сказано выше, создание цифровых двойников производств создает дополнительные угрозы для предприятия (поскольку повышает его уязвимость для информационных атак).

Российская нефтегазовая отрасль в настоящее время вынуждена функционировать в сложных геополитических (санкционное давление $[2,12])$ и геоэкономических (высокая волатильность цен на нефть и газ, связанная с ростом добычи нетрадиционной нефти и газа в США [16] и формирования единого мирового рынка газа благодаря развитию технологий его сжижения $[15,17])$. При этом санкции направлены не только против отечественного нефтегазового комплекса [23], но и против России в целом, вследствие чего, в частности, ограничиваются поставки передовых информационных технологий. Кроме того, наша страна зависит от закупок иностранной высокотехнологичной продукции, что, с высокой вероятностью, ставит российские производства под контроль иностранных поставщиков (которые имеют возможность без ведома со стороны российских компаний дистанционно менять настройки и режимы работы оборудования и программного обеспечения, получать доступ к хранящейся информации и т. д.). Формально такое вмешательство осуществляется для повышения качества работы оборудования и программного обеспечения, однако вполне вероятна ситуация, когда иностранные поставщики откроют этот доступ для правительств своих государств в целях блокировки деятельности ключевых российских компаний (к числу которых относятся и нефтегазовые). Отдельно подчеркнем, что, благодаря механизму санкций, США могут контролировать не только производственную деятельность иностранных предприятий, но и получать фактический контроль над управлением (как это произошло с активами Олега Дерипаски и китайской компанией Xiaomi).

Это означает, что, с точки зрения угроз своей экономической безопасности, обусловленных развитием технологий, национальные нефтегазовые компании вынуждены выбирать между отказом от использования новых организационных и технологических моделей (чтобы не допустить риска вмешательства со стороны враждебно настроенных экономических и политических агентов; примером его, с определенными оговорками, может быть компания «Сургутнефтегаз»), и тем самым оставаться в рамках предыдущего технологического уклада (этот 
подход можно назвать консервативным или автономным), и встраиванием в глобальную мирохозяйственную систему, где будет возможно формирование эффективных транснациональных метафирм, деятельность которых будет контролироваться внешними игроками (такой подход мы можем назвать глобалистским; он был реализован Олегом Дерипаской для снятия санкций с контролируемых им компаний). Отметим, что консервативный (автономный) подход в большей мере отвечает интересам государства, тогда как глобалистская модель соответствует запросам собственников компаний. Это дополнительно усложняет выбор эффективной модели обеспечения экономической безопасности.

Сказанное выше означает, что:

1. Единую модель обеспечения экономической безопасности предприятий российского нефтегазового комплекса построить невозможно из-за принципиальных различий в их модели управления и в задачах, которые они решают;

2. Модель обеспечения экономической безопасности предприятий нефтегазового комплекса будет строиться путем сочетания инструментов, присущих автономному (консервативному) и глобалистскому подходам. Фактически, с учетом сказанного выше, предприятия будут самостоятельно выстраивать баланс между инструментами с учетом специфики своих задач;

3. Весьма вероятно, что выбор модели обеспечения экономической безопасности конкретной нефтегазовой компании будет осуществляться с учетом тех условий, в которые ее поставят внешние игроки (санкционное давление и т. д.). Это, к сожалению, создает риски того, что государство может попытаться де-факто национализировать ведущие нефтегазовые компании, чтобы защититься от рисков перехвата контроля над ними (такая национализация может быть осуществлена в мягкой форме, путем выкупа компаний и слияния их с уже существующими государственными нефтегазовыми компаниями).

Таким образом, может быть поставлена задача составления перечня инструментов обеспечения экономической безопасности, присущих консервативному и глобалистскому подходам, и разработки рекомендаций по их сочетанию с учетом специфики деятельности конкретных нефтегазовых компаний.

Еще одна важная проблема заключается в изменении характера запасов углеводородов в нашей стране. Происходит их непрерывное смещение в регионы, находящиеся в сложных географических (морской шельф), климатических (Арктическая зона Российской Федерации) и геологических (малые запасы, большая глубина залегания и т. д.) условиях [23] (в отдельных случаях име- ет место совмещение разных факторов - часть добычи углеводородов в нашей стране уже ведется на шельфе Северного Ледовитого океана) [30]. Это ведет к росту издержек на нефтедобычу, которые дополнительно увеличиваются за счет того, что новые добывающие регионы характеризуются низкой степенью хозяйственного освоения, в силу чего требуется строительство в них новой производственной и транспортной инфраструктуры. Кроме того, эти регионы исключительно неустойчивы с экологической точки зрения, что, с одной стороны, также увеличивает затраты нефтегазовых компаний (из-за необходимости принимать меры по экологической безопасности своих производств), а, с другой стороны, может стать причиной огромного ущерба для экологии в случае техногенной катастрофы. Все эти факторы в совокупности предъявляют повышенные требования к обеспечению экономической безопасности нефтегазовых компаний.

Еще одним важным моментом является то, что нефтегазовые компании в ходе своей производственной деятельности осуществляют исключительно капиталоемкие проекты. Издержки на реализацию этих проектов могут создавать угрозы для финансовой устойчивости этих компаний. По этой причине нефтегазовые предприятия должны уделяться сбалансированности своего портфеля финансирования и инвестиционных проектов.

Сказанное выше позволяет нам идентифицировать основные направления обеспечения экономической безопасности нефтегазовой компании [11]:

1. Финансовая безопасность (финансовая стабильность компании). Этот параметр является традиционным индикатором экономической безопасности предприятия и входит в системы оценки ЭБ компаний независимо от их отраслевой принадлежности;

2. Ресурсная безопасность (обеспеченность компании запасами углеводородов, качество этих запасов). Этот показатель специфичен для нефтегазовой отрасли (точнее, для добывающих предприятий в целом; специфика нефтегазовой отрасли отражается через учет запасов конкретного ресурса);

3. Производственная безопасность (независимость компании от внешних провайдеров технологических активов и сервисов $[1,18,39])$. Этот параметр по своей природе также универсален, поскольку все компании зависят от внешних источников ресурсов и компетенций. Интересно отметить, однако, что в существующих работах по анализу ЭБ этот параметр нигде не учитывается [40]. Тем не менее, ввести его для оценки ЭБ компании нефтегазовой отрасли необходимо, поскольку в этой сфере деятельности сформировалась глубокая специализация, и зависимость добывающих 
компаний от внешних профильных провайдеров высокотехнологичных сервисов очень высока [23, 37, 38];

4. Политическая безопасность (отсутствие международных санкций против компании). Учет этого направления безопасности необходим в современных геополитических и геоэкономических условиях, когда санкции стали инструментом не только политического давления, но и недобросовестной конкуренции [3, 8];

5. Цифровая безопасность (способность предприятия эффективно противостоять цифровым угрозам). Введение этого параметра необходимо в связи с происходящей цифровой трансформацией экономики.

Эти факторы экономической безопасности, очевидно, тесно связаны друг с другом. Финансовая стабильность компании, в частности, обуславливает способность предприятия осваивать свои запасы углеводородов. В свою очередь, качество запасов (с одной стороны, затраты на их освоение и эксплуатацию [10], а с другой стороны - объем этих запасов, который определяет величину будущих денежных потоков компании), уровень сотрудничества с внешними контрагентами (которые предоставляют свои ресурсы и компетенции для повышения эффективности деятельности нефтегазовой компании $[37,38])$ и политическая безопасность (доступность внешнего финансирования) будут в значительной степени определять финансовую безопасность компании. От политической безопасности также зависит способность компании привлекать внешних контрагентов (нефтесервисных операторов). Обеспеченность компании финансовыми ресурсами будет обуславливать величину ее инвестиций в цифровую безопасность. Наконец, для сотрудничества с внешними контрагентами компания также должна обладать финансовой устойчивостью, поскольку внешние ресурсы предоставляются на временной и платной основе и в случае неспособности компании внести плату за них в доступе к этим ресурсам ей будет отказано [21]. Это означает, что для адекватной оценки уровня ЭБ нефтегазовой компании недостаточно оценить только ее финансовую безопасность - необходимо понимать уровень ее безопасности и по другим направлениям деятельности.

Для оценки финансовой безопасности можно использовать показатель финансовой устойчивости ФУ [31]. Он удобен тем, что он принимает значения от 0 до 1, и поэтому может быть легко использован в качестве элемента интегрального показатель ЭБ. Рассчитывается он по следующей формуле:

$\Phi У=\frac{\text { Собственный капитал+Долгосрочные обязательства }}{\text { Валюта баланса }}$.
Поскольку показатель финансовой устойчивости является относительным, то все остальные частные показатели ЭБ также должны быть относительными и принимать тот же диапазон значений.

Ресурсную безопасность можно оценивать при помощи двух показателей:

1. Коэффициент возмещения запасов КВБ:

$$
\text { КВБ }=\frac{\text { Новые запасы }}{\text { Выбывающие запасы }} .
$$

Под новыми запасами понимаются запасы углеводородов, которые в отчетном периоде ставятся на баланс компании (т. е. запасы, которые были открыты, оценены и зарегистрированы). Выбывающие запасы - это запасы, которые были исчерпаны в течение отчетного периода. Если $\mathrm{KBБ}<1$, то ресурсная база компании уменьшается, что негативно сказывается на ее перспективах долгосрочного дохода.

Поскольку КВБ может принимать значения больше 1, то мы предлагаем ввести откорректированное значение этого показателя КВБ мости с показателем финансовой устойчивости:

$$
\mathrm{KBБ}_{\text {corr }}=\left\{\begin{array}{cc}
\text { КВБ, } & \text { КВБ } \leq 1, \\
1, & \text { КВБ }>1 .
\end{array}\right.
$$

2. Коэффициент доступности запасов КДЗ:

$$
\text { КдЗ }=\frac{\text { тд3 }}{3},
$$

ТД3 - труднодоступные запасы компании (запасы, расположенные в неблагоприятных географических, климатических и/или геологических условиях);

3 - совокупный объем запасов компании.

Мы предлагаем оценивать ресурсную безопасность компании при помощи показателя ресурсной безопасности РБ, который рассчитывается по следующей формуле:

$$
\text { РБ }=\sqrt{\left(1+\text { КВБ }_{\text {corr }}\right)(1+\text { КД3) }}-1 .
$$

Необходимость прибавления единицы (и ее последующего вычитания) в приведенной выше формуле связана с тем, что один из показателей КВБсоrr или КДЗ может быть равен нулю. Однако это не означает, что интегральная ресурсная безопасность равна нулю. Прибавление единицы позволяет избежать равенства нулю показателя РБ в ситуации, когда один из показателей КВБсоrr или КДЗ равен нулю.

Оценивать производственную безопасность можно оценивать при помощи показателя производственной безопасности ПБ, который будет рассчитываться при помощи следующей формулы: 


$$
\text { ПБ }=\frac{\text { СПА }}{\Pi \Pi \mathrm{A}}
$$

где

СПА - величина собственных производственных активов компании (в денежном выражении);

ППА - величина полных производственных активов компании (в денежном выражении). Полные производственные активы, помимо собственных производственных активов, включают те активы, которые были временно привлечены у сторонних провайдеров на основе договоров аренды, лизинга, фрахта, аутсорсинга и т. д. [22]. Они, с одной стороны, позволяют увеличить ресурсную базу компании, но, с другой стороны, ставят ее в зависимость от поставщиков этих ресурсов.

Показатель производственной безопасности ПБ позволяет оценить независимость компании от внешних провайдеров активов. По своему смыслу он противоположен показателю сервисного рычага [22] (который оценивает, во сколько раз величина задействованных компанией производственных активов превышает ее собственные активы). В современных геополитических условиях российские нефтегазовые компании вынуждены искать компромисс между максимизацией значения показателя сервисного рычага (т. е. активным использованием внешних активов, что позволяет добиться гибкости при формировании производственной базы и снизить издержки на нее) и максимизацией показателя производственной безопасности (который ведет к росту издержек на формирование активов и управление ими, но минимизирует риски отказа в доступе к активам). Очевидно, что стремиться к полной самообеспеченности производственными активами для компании нецелесообразно. В настоящее время следует рекомендовать нефтегазовым компаниями при выборе провайдеров активов отдавать предпочтение российским предприятиям.

Для оценки политической безопасности компании мы предлагаем использовать показатель санкционной безопасности СБ, который рассчитывается по следующей формуле:

$$
\mathrm{CБ}=\frac{\mathrm{БC}}{\mathrm{B}} \text {, }
$$

где

БС - доля бизнеса компании, затронутая политическими санкциями;

Б - совокупная величина бизнеса компании.

Наибольшие трудности представляет корректная оценка цифровой безопасности. Хотя в настоящее время предложены различные подходы к количественному определению ее величины [4, 5, 7, 33, 34, 35], ни один из них нельзя назвать бесспорным из-за сложности природы цифровой безопасности. При этом, в отличие от всех перечисленных выше видов безопасности, при оценке цифровой безопасности приходится широко использовать экспертные методы, поскольку наблюдаемые характеристики у цифровой безопасности отсутствуют.

Для оценки цифровой безопасности предприятия мы будем использовать показатель цифровой безопасности ЦБ, рассчитываемый следующим образом:

$$
\text { ЦБ }=\sqrt[n]{\prod_{i=1}^{n} \frac{R_{i}}{10}}
$$

где

$n$ - число анализируемых направлений обеспечения цифровой безопасности;

$R_{i}$ - рейтинг компании по і-му направлению обеспечения информационной безопасности. Определяется экспертно на основе сопоставления с лучшими мировыми аналогами и принимает значения в диапазоне от 1 до 10.

Интегральный показатель экономической безопасности нефтегазовой компании ИЭБ можно рассчитать по следующей формуле:

$$
\text { иЭБ }=\sqrt[4]{(1+\text { ФУ)(1+ РБ)(1+ ПБ)(1+СБ)(1+ ЦБ) }}-1 .
$$

В приведенной выше формуле для расчета интегрального показателя экономической безопасности использован алгоритм свертки на основе среднего взвешенного геометрического. Это связано с тем, что все частные показатели экономической безопасности, предложенные нами выше (финансовая устойчивость, ресурсная безопасность, производственная безопасность и санкционная безопасность) являются относительными.

Для оценки экономической безопасности нефтегазовой компании мы предлагаем использовать шкалу, представленную в табл. 1.

Интегральный показатель экономической безопасности ИЭБ служит для общей оценки ЭБ. Идентифицировать состояние ЭБ нефтегазового предприятия более корректно можно при помощи частных показателей экономической безопасности. Для них мы предлагаем следующие диапазоны значений:

- не менее 0,9 - высокий уровень безопасности;

- не менее 0,75 - допустимый уровень безопасности;

- менее 0,75 - недостаточный уровень безопасности.

Разница в шкалировании частных показателей и интегрального показателя ЭБ объясняется разной природой этих показателей. В интегральном показателе недостаточный уровень безопасности по отдельным направлениям может частично компенсироваться высоким уровнем безопасности по другим направлениям. 
Таблица 1.

Шкала оценки уровня экономической безопасности нефтегазовой компании

\begin{tabular}{|c|c|l|}
\hline $\begin{array}{c}\text { Диапазон значений } \\
\text { показателя ИЭБ }\end{array}$ & $\begin{array}{c}\text { Уровень экономиче- } \\
\text { СКой безопасности }\end{array}$ & \multicolumn{1}{|c|}{ Комментарии } \\
\hline $0,9<И Э Б \leq 1$ & Высокий & $\begin{array}{l}\text { Компания характеризу- } \\
\text { ется высоким уровнем } \\
\text { устойчивости ко всем } \\
\text { ключевым угрозам ее } \\
\text { деятельности }\end{array}$ \\
\hline $0,75<$ ИЭБ $\leq, 9$ & Приемлемый & $\begin{array}{l}\text { По отдельным направ- } \\
\text { лениям деятельности } \\
\text { компания недостаточно } \\
\text { защищена от угроз }\end{array}$ \\
\hline $0,5<И Э Б \leq 0,75$ & Допустимый & $\begin{array}{l}\text { Компания в целом недо- } \\
\text { статочно защищена от } \\
\text { угроз, однако риски для } \\
\text { ее деятельности не носят } \\
\text { критического характера }\end{array}$ \\
\hline $0,25<И Э Б \leq 0,5$ & Неприемлемый & $\begin{array}{l}\text { По отдельным направле- } \\
\text { ниям деятельности риски } \\
\text { для компании являются } \\
\text { критическими }\end{array}$ \\
\hline ИЭБ $\leq 0,25$ & Угрожающий & $\begin{array}{l}\text { Риски для компании } \\
\text { являются критическими } \\
\text { по всем или большинству } \\
\text { направлений деятель- } \\
\text { ности }\end{array}$ \\
\hline & & \\
\hline
\end{tabular}

Предложенные пороговые значения показателей в приведенных выше шкалах носят рекомендательный характер и ориентированы скорее на потребности нефтегазовых компаний, которые являются национально ориентированными. Предприятия нефтегазовой отрасли, которые, напротив, ориентированы на интеграцию в мировое экономическое пространство (или, точнее, предприятия, собственники которых в качестве приоритетного вектора развития видят встраивание себя не в национальную, а в глобальную элиту), могут установить иные значения этих показателей.
Таким образом, адаптация предложенной выше методики оценки к специфическим потребностям отдельных нефтегазовых компаний осуществляется не за счет введения альтернативных показателей ЭБ или использования иных методик расчета рекомендованных нами показателей, а путем применения различных шкал пороговых значений. За счет этого можно примирить унифицированный подход к формированию системы показателей ЭЮ нефтегазовой компании и необходимость адаптации методики оценки ЭП нефтегазовой компании к запросам отдельных предприятий.

Наши выводы:

- в настоящее время технологическая, организационная, геополитическая и производственная среда, в которой ведут свою деятельность нефтегазовые компании, претерпевает глубокие изменения. Эти изменения необходимо учитывать при анализе экономической безопасности нефтегазовой компании. В частности, недостаточно ограничиваться анализом показателей деятельности самой компании - следует принимать во внимание качество ее взаимодействия с внешними контрагентами;

- в качестве основных направлений обеспечения экономической безопасности предприятия мы идентифицируем финансовую безопасность, ресурсную безопасность, производственную безопасность и политическую безопасность. Только комплексный анализ этих направлений позволяет объективно оценить реальное состояние ЭБ нефтегазовой компании;

- предложенная нами система показателей ЭБ, включающая набор частных показателей ЭБ (для оценки ключевых направлений обеспечения ЭБ нефтегазовой компании) и интегральный показатель ЭБ нефтегазового предприятия позволяют адекватно оценить уровень ЭБ компании нефтегазовой отрасли и принимать решения по управлению ею.

\section{ЛИТЕРАТУРА}

1. Богоявленский В. И. Стратегия развития нефтегазовой отрасли России и импортозамещение // Управление качеством в нефтегазовом комплексе. 2015. - № 4. - С. 17-18.

2. Борисова А.Р., Кислицын С.В. Влияние санкций США на топливно-энергетический комплекс России // США и Канада: экономика, политика, культура. 2017. - № 3. - С. 84-96.

3. Боровский Ю.В. Советский и российский ТЭК как объекты западных санкций: политическое соперничество или экономическая конкуренция? // Вестник МГИмо Университета. - 2019. - № 3. - С. 42-60.

4. Бугорский В.Н., Стельмашонок Е.В. Экономические проблемы информационной безопасности: новый взгляд // Вестник ИНЖЭКОНа. Серия: Экономика. 2013. - № 1. - С. 67-71.

5. Бугорский В.Н., Стельмашонок Е. В. Методика принятия решения об использовании аутсорсинга в области информационных технологий с учетом требований безопасности // Петербургский экономический журнал. - 2015. - № 4. - С. 163-169. 
6. Веретехин А.В. Совершенствование механизма управления промышленным предприятием в аспекте экономической безопасности // Вестник СамГУПС. - 2017. - № 3. - C. 99-106.

7. Волкодаева А.В., Балановская А.В. Оценка уровня информационной безопасности промышленных предприятий // Вестник Самарского муниципального института управления. - 2013. - № 3. - С. 7-18.

8. Гадзацев К.В. Политическое давление и информационная война США против России на европейском газовом рынке: состояние и перспективы // Информационные войны. - 2020. - № 1. - С. 11-17.

9. Глазьев С.Ю. Мирохозяйственные уклады в глобальном экономическом развитии // Экономика и математические методы. - 2016. - Т. 52. - № 2. - С. $3-29$.

10. Глушенкова М.В., Мехеев Е.В., Судыкин С.Н., Валовский К.В. Анализ изменения эксплуатационных затрат в зависимости от вязкости добываемой нефти // Проблемы экономики и управления нефтегазовым комплексом. - 2014. - № 12. - С. 11-14.

11. Головко М.В., Плотников В.А. Неэкономические факторы экономической безопасности // Национальные интересы: приоритеты и безопасность. - 2019. - Т. 15. - № 1. - С. 35-52.

12. Горбунова 0.А. Воздействие санкций на функционирование российских компаний нефтегазового сектора на мировом рынке нефти и газа // Вестник евразийской науки. - 2018. - Т. 10. - № 2. - С. 13.

13. Дмитрук Е.В., Ляшенко А.Н., Таращанский М.Т. Модели экономической безопасности предприятия и его репутации // Управління проектами та розвиток виробництва: 3б.наук.пр. - 2010. - № 1 (33). - С. 93-101.

14. Дородных Е.Е., Курбанов А.Х. Трансформация управления производством на предприятиях оборонно-промышленного комплекса в условиях цифровизации экономики // Проблемы экономики и управления нефтегазовым комплексом. - 2019. - № 6. - С. 57-61.

15. Заболотский С.А. Современные тенденции поставок и потребления сжиженного природного газа в мире // Проблемы экономики и управления нефтегазовым комплексом. - 2013. - № 12. - С. 45-51.

16. Золина С.А., Копытин И.А., Резникова 0.Б. «Сланцевая революция» в США как главный драйвер перестройки мирового рынка нефти // Контуры глобальных трансформаций: политика, экономика, право. - 2019. - Т. 12. - № 6. - С. 71-93.

17. Иванова К.С. Перспективы и проблем развития производства и сбыта СПГ в России // Проблемы экономики и управления нефтегазовым комплексом. 2019. - № 7. - С. 46-50.

18. Кершенбаум В.Я. Направления импортонезависимости в нефтегазовом комплексе России // Управление качеством в нефтегазовом комплексе. - 2016. - № 1. - С. 9-10.

19. Клейнер Г.Б. Экономика экосистем: шаг в будущее // Экономическое возрождение России. - 2019. - № 1. - С. $40-45$.

20. Кобылко А.А. Экосистемные компании: границы и этапы развития // Экономическая наука современной России. - 2019. - № 4. - С. 126-136.

21. Котляров И.Д. Негативные следствия роста экономики услуг // Известия высших учебных заведений. Серия: Экономика, финансы и управление производством. - 2013. - № 2. - С. 83-90.

22. Котляров И.Д. Сервисный рычаг и обеспечение доступа к производственным активам предприятия // Вестник Нгуэу. - 2014. - № 4. - С. 164-172.

23. Котляров И.Д. Аутсорсинговая модель организации российской нефтегазовой отрасли: проблемы и пути решения // Вопросы экономики. - 2015. - № 9. - С. 45-64.

24. Котляров И.Д. Метафирма как форма организации хозяйственной деятельности // Управление экономикой: методы, модели, технологии. Материалы XV Международной научной конференции. В 2 томах. - Т. 1. - Уфимский государственный авиационный технический университет: Уфа, 2015. - С. 88-91.

25. Курбанов А.Х. Экономико-математическая модель оценки организационно-экономической эффективности внедрения аутсорсинга // Проблемы экономики и управления нефтегазовым комплексом. - 2012. - № 2. - С. 40-44.

26. Курбанов А.Х., Плотников В.А. Аутсорсинг: история, методология, практика. М.: Инфра-М, 2012. - 112 с.

27. Нуреев Р.М., Карапаев 0.В. Три этапа становления цифровой экономики // Journal of Economic Regulation. - 2019. - Т. 10. - № 2. - С. 6-27.

28. Орехова С.В., Заруцкая В.С. Интеграция бизнеса: эволюция подходов и новая методология // Журнал экономической теории. - 2019. - Т. 16. - № 3. - С. 554-574.

29. Плотников В.А. Цифровизация производства: теоретическая сущность и перспективы развития в российской экономике // Известия СанктПетербургского государственного экономического университета. - 2018. - № 4. - С. 16-24.

30. Плотников В.А., Кутепова М.В. Управление экономической безопасностью нефтяных компаний (на примере оценки и снижения рисков реализации проектов освоения нефтяных месторождений Арктического региона России) // Известия Юго-Западного государственного университета. Серия: Экономика. Социология. Менеджмент. - 2017. - Т. 7. - № 1. - С. 39-49.

31. Рогова Е.М. Ткаченко Е.А. Финансовый менеджмент. М.: Юрайт, 2011. - 540 с.

32. Смородинская Н.В., Катуков Д.Д. Распределенное производство и «умная» повестка национальных экономических стратегий // Экономическая политика. - 2017. - Т. 12. - № 6. - С. 72-101.

33. Стельмашонок Е.В., Соколовская С.А. Стратегическое управление информационной безопасностью предприятия на основе сбалансированной системы показателей // Вестник ИНЖЭКОНа. Серия: Экономика. - 2010. - № 6. - С. 112-117.

34. Стельмашонок Е.В., Стельмашонок В.Л. Методические аспекты моделирования системы защиты информации в организации // Петербургский экономический журнал. - 2019. - № 2. - С. 64-70.

35. Стельмашонок Е.В., Тараторин Д.И. Моделирование системы информационной безопасности на предприятии распределенного типа // Вестник ИНжэКоНа. Серия: Экономика. - 2009. - № 6. - С. 185-190.

36. Устюжанина Е.В., Сигарев А.В., Шеин Р.А. Цифровая экономика как новая парадигма экономического развития // Экономический анализ: теория и 
практика. - 2017. - Т. 16. - № 12. - С. 2238-2253.

37. Фадеев А.М., Ларичкин Ф.Д. Стратегические приоритеты устойчивого развития рынка сервисных услуг при освоении шельфовых месторождений // Записки Горного института. - 2011. - Т. 191. - С. 197-204.

38. Хвалевич А.В. Развитие мирового рынка услуг по добыче нефти и газа // Российский внешнеэкономический вестник. - 2015. - № 8. - С. 116-126.

39. Шмаль Г.И. Импортонезависимость НГК. Возможна ли? // Управление качеством в нефтегазовом комплексе. - 2015. - № 4. - С. 9-12.

40. Экономическая безопасность России: Общий курс / Под ред. В.К. Сенчагова. М.: Дело, 2005. - 896 с.

\section{○ Бабенков Валерий Иванович (vi_babenkov@mail.ru), Жуков Иван Федорович (ivan-zhukov-1995@mail.ru),}

Фролов Александр Олегович (frolov@live.ru).

Журнал «Современная наука: актуальные проблемы теории и практики»

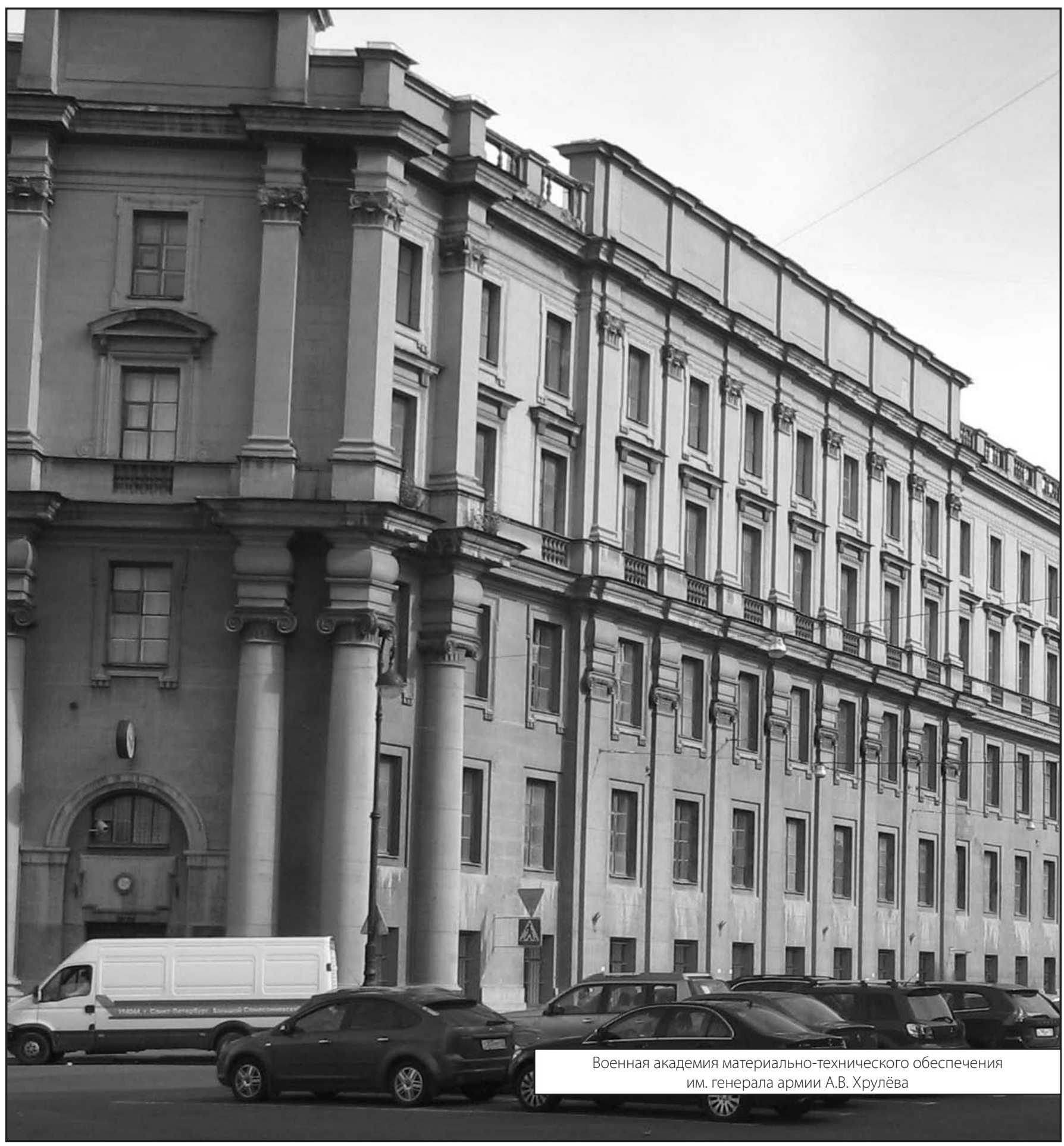

